\title{
Binary mixtures of two anionic polysaccharides simulating the rheological properties of oxidised starch**
}

\author{
Marek Sikora ${ }^{1}$, Anna Dobosz ${ }^{1}$, Greta Adamczyk ${ }^{1}$, Magdalena Krystyjan ${ }^{1}$, Stanisław Kowalski ${ }^{1}$, \\ Piotr Tomasik, and Edyta M. Kutyła-Kupidura ${ }^{1}$ \\ ${ }^{1}$ Department of Carbohydrates Technology, Faculty of Food Technology, University of Agriculture in Kraków, Balicka 122 , \\ 30-149 Kraków, Poland \\ ${ }^{2}$ Kraków College of Health Promotion, Krowoderska Street 73, 31-158 Kraków, Poland
}

Received June 1, 2016; accepted January 25, 2017

\begin{abstract}
Modifications of starches are carried out to improve their industrial usefulness. However, the consumers prefer natural products. For this reason, various methods of starch properties modification are applied to replace those requiring the use of chemical reagents. The aim of this study was to determine whether it is possible to use binary pastes, containing normal potato starch and xanthan gum, as substitutes of chemically modified starches (with oxidised starch E 1404 pastes as an example). Flow curves with hysteresis loops, apparent viscosity at constant shear rate of $50 \mathrm{~s}^{-1}$ and in-shear structural recovery test with pre-shearing were applied to study the rheological properties of the pastes. It was found that two anionic hydrocolloids, potato starch and xanthan gum, can form binary systems with thickening properties, provided that their proportions are adequately adjusted. Some of the binary pastes under investigation exhibited rheological properties resembling pastes of starch oxidised with hypochlorite (E 1404). The way of tailoring the binary pastes properties is presented.

Keywords: oxidised starch, potato starch, rheological properties, xanthan gum
\end{abstract}

\section{INTRODUCTION}

Developments in food technology, changes in culinary habits among populations and attempts at limiting the energetic value of meals, evoked a demand for novel texturising agents for food. Such agents should also conform to regulations associated with digestibility, health precautions, storage stability and resistance to microorganisms. There are several possibilities to meet, at least in part, demands of this kind. Thus, selection among polysaccharide hydrocolloids seems to be the most obvious.

*Corresponding author e-mail: rrsikora@cyf-kr.edu.pl

**This project was financed from funds provided by the National Science Centre of Poland awarded on the basis of decision number DEC-2011/03/B/NZ9/00152.
In the case of starches, both their physicochemical and functional properties depend on the selection of starch of a given botanical origin (Singh et al., 2003; Swinkels, 1985; Tegge, 2010; Whistler and BeMiller, 1977). Rheological and textural properties of pastes and gels of a given starch are determined by the pasting regime, eg concentration, time and temperature, all influencing the degree of pasting and accompanying degradation of amylose and amylopectin chains (Appelqvist and Debet, 1997; Sikora et al., 2015; Tomasik and Schilling, 1998a, 1998b). Also, the rheological properties of starch systems are dependent on the $\mathrm{pH}$ and temperature changes as well as on mechanical forces (Arocas et al., 2009; Kaur et al., 2012; Rutkowski et al., 2003).

In order to enhance the industrial suitability of starches, their modifications are undertaken. They can be chemical, physical, enzymatic (or combinations of them), resulting in a notable number of starch derivatives (Kaur et al., 2012; Pietrzyk and Fortuna, 2006; Tegge, 2010). However, national food laws of most countries put some limits on the levels of chemically modified starches (for instance, oxidised, starch, starch phosphates, esters of starch with organic acids, etherified starch and so on) for nutritional purposes (Compendium, 2011; Le Than et al., 2007).

Oxidised starch (OS), with code number E 1404, is produced by the action of sodium hypochlorite over normal starch. OS is commonly used as a thickener, stabiliser and emulsifier in various types of food (Compendium, 2011; Rutkowski et al., 2003). It should not be used without any limit. According to the Codex Alimentarius (2014), the daily intake limit for infants and youngsters should not exceed

(C) 2017 Institute of Agrophysics, Polish Academy of Sciences 
$5000 \mathrm{mg} \mathrm{kg}^{-1}$ body weight. It is one of the reasons of some distrust towards that food ingredient and this point of view spreads onto other chemically modified food additives. That argument rationalises the attempts at looking for their substitutes.

Recently, binary hydrocolloid systems evoked consi derable interest as filling, thickening and texturising agents (Alloncle et al., 1989; Arocas et al., 2009; Kowalski et al., 2008; Sikora et al., 2010 and references therein). Such binary hydrocolloid blends could be tailored, provided that interactions between polysaccharides in such mixtures are properly recognised (Kowalski et al., 2008). Morris (1991) distinguished four types of networks formed in binary hydrocolloid mixtures depending on interactions between the components.

They were:

- network formed of one hydrocolloid and a second hydrocolloid (non-gelled) entrapped inside that network;

- network formed by both hydrocolloids which built independent mutually interpenetrating networks;

- network of both hydrocolloids paste separating into two phases, and

- a coupled, common network.

The botanical origin of starch as a component of such mixtures is crucial, as the hydrocolloids used can be electrically either neutral or ionic (Ramsden, 2004). Normal potato starch (NPS) is the sole anionic starch. Therefore, on blending NPS with other anionic polysaccharides a decrease in viscosity of resulting blends can be observed. Such behaviour was documented in the case of blends of NPS and xanthan gum (XG) (Kowalski et al., 2008). Nevertheless, binary NPS-XG systems have been fairly intensively studied (Baranowska et al., 2008; Krystyjan et al., 2013; Mandala et al., 2002; Sikora et al., 2008b) and used with success in thickening desserts, sauces and syrups (Sikora et al., 2007, 2008a). However, there is no research found in the literature that aims at comparison of the thickening properties of NPS-XG blends with those of OS pastes.

The aim of the study presented in this paper was to investigate binary NPS pastes containing small amounts of xanthan gum. A way of tailoring the properties of NPS-XG binary pastes for using them as substitutes of chemically modified starches is discussed, taking oxidised starch E 1404 (OS) pastes as an example, thus pointing to the possibility of OS (E 1404) substitution with NPS-XG binary mixtures.

\section{MATERIALS AND METHODS}

Normal potato starch (NPS) was isolated from potatoes of the Tajfun variety, purchased from the Experimental Station of Variety Evaluation in Węgrzce, Poland. The starch contained $86.92 \%$ dry mass, $111.9 \mathrm{mg} 100 \mathrm{~g}^{-1}$ d.m. total phosphorus, $0.13 \%$ fat and $31.99 \%$ amylose. Its aqueous solubility was 14.66 and $20.94 \%$ at 80 and $95^{\circ} \mathrm{C}$, respectively. Water binding capacity of that starch was estimated at 37.34 and $69.34 \mathrm{~g}^{-1} \mathrm{~g} \mathrm{~d} . \mathrm{m}$. at 80 and $95^{\circ} \mathrm{C}$, respectively. Oxidised starch (OS) (LU-1404-1) was purchased from WPPZ S.A. in Luboń, Poland. It was prepared by oxidation of potato starch with sodium hypochlorite. Xanthan gum (XG) from Xanthomonas campestris (G1253-500G, Lot\#100M0218V) was purchased from Sigma-Aldrich (St. Louis, USA).

Suspensions of 2, 3, 4 and 5\% (d.m.) NPS containing XG at concentrations of $0,0.010,0.075$ and $0.150 \%$ were placed in $100 \mathrm{~cm}^{3}$ beakers and supplemented with distilled water to a total weight of $100 \pm 0.00 \mathrm{~g}$. The suspensions were agitated for $10 \mathrm{~min}$ at room temperature, at 400 r.p.m., followed by $30 \mathrm{~min}$ of heating and stirring at 400 r.p.m. in a water bath at either 80 or $95^{\circ} \mathrm{C}$. Suspensions of $2-5 \%$ (d.m.) OS were agitated at 400 r.p.m. at room temperature for $10 \mathrm{~min}$ and then heated with continuous stirring (400 r.p.m.) at $95^{\circ} \mathrm{C}$ for $30 \mathrm{~min}$. Pasting of OS samples only at $95^{\circ} \mathrm{C}$ aimed at simulating conditions similar to the industrial ones (cooking), while the pastes of NPS were heated both at 80 and $95^{\circ} \mathrm{C}$, which was aimed at the acquisition of various pastes with an addition of XG, differentiated by rheological properties, and in this way at the enhancement of the probability of producing pastes with rheological properties resembling those of OS properties.

Arheometer, RheoStress RS 1 (Gebreuder Haake GmbH, Karlsruhe, Germany), was used. It operated with a measuring system consisting of two coaxial cylinders Z41 Ti. Temperature of $50^{\circ} \mathrm{C}$ was maintained during the measurements. The measurements were run in duplicates.

In the hysteresis loop test with the rheometer RS 1 at controlled shear rate, within $600 \mathrm{~s}$ an increase from 0.1 to $300 \mathrm{~s}^{-1}$ followed by $120 \mathrm{~s}$ maintaining constant shear rate at $300 \mathrm{~s}^{-1}$ and a decrease in the shear rate from 300 to $0.1 \mathrm{~s}^{-1}$ within $600 \mathrm{~s}$ were noted. The areas of the hysteresis loop were calculated by summation of the areas of trapeziums situated between ascending and descending curves. The power of thixotropy in the volume of the sample was calculated as a function of the shear rate (Sikora et al., 2015). Rheological properties were analysed by fitting the Ostwald - de Waele rheological model (1) to the flow curves taken at shear rate increasing from 0 to $300 \mathrm{~s}^{-1}$ :

$$
\tau=k \dot{\gamma}^{n}
$$

where: $\tau$ is the shear stress (Pa), $K$ is the consistency coefficient $\left(\mathrm{Pa} \mathrm{s}^{\mathrm{n}}\right), \dot{\gamma}$ is the shear rate $\left(\mathrm{Pa} \mathrm{s}^{-1}\right)$, and $n$ is the flow behaviour index. The estimations were duplicated.

In-shear structural recovery test with pre-shearing was carried out according to the procedures of Mezger (2002), Achayuthakan and Suphantharika (2008), Wang et al. (2009; 2010), modified by Sikora et al. (2015), as follows: 1) preshearing - a constant shear rate of $100 \mathrm{~s}^{-1}$ for $\left.30 \mathrm{~s}, 2\right)$ relaxation - a zero shear rate for $300 \mathrm{~s}, 3$ ) a constant shear rate 
of $1 \mathrm{~s}^{-1}$ for $\left.120 \mathrm{~s}, 4\right)$ a constant shear rate of $300 \mathrm{~s}^{-1}$ for $60 \mathrm{~s}$, 5) a constant shear rate of $1 \mathrm{~s}^{-1}$ for $240 \mathrm{~s}$. The results enabled calculations of the degree of structure recovery (DSR) of the pastes according to Wang et al. $(2009 ; 2010)$ - the ratio of the average apparent viscosity in the fifth (obtained in the first $120 \mathrm{~s}$ ) and the third step were considered.

Apparent viscosity was taken within $10 \mathrm{~min}$ at constant shear rate of $50 \mathrm{~s}^{-1}$.

Statistica 12.0 (Statsoft, Tulsa, OK., USA) involving one- and two-way analysis of variance (ANOVA) was applied. Significant differences at $\alpha=0.05$ were indicated using Duncan's test.

\section{RESULTS AND DISCUSSION}

As shown in Table 1 , consistency coefficients $K$ and flow behaviour indices $n$ of the NPS pastes prepared at given temperature, that is either 80 or $95^{\circ} \mathrm{C}$, increased with the concentration of NPS in the paste.

Consistency coefficient $(K)$ and flow behaviur index $(n)$ depended on the NPS paste concentration as well as on the temperature of the paste preparation. Thus, in 2 and 3\% NPS pastes, as temperature of pasting increased from 80 to $95^{\circ} \mathrm{C}$ the consistency of the paste increased. It could reflect a higher degree of swelling and pasting of starch granules. However, in more concentrated 4 and 5\% NPS pastes $K$ decreased with an increase in pasting temperature. It could reflect the effect of water deficiency obstructing complete pasting of granules. That effect was confirmed in our recent paper (Sikora et al., 2015). Flow behaviour indices, $n$, increased with an increase in temperature of pasting and the pastes concentration.

The effect of admixture of XG to NPS pastes depended on the amount of XG added, NPS paste concentration and temperature of the paste preparation. Admixture of $\mathrm{XG}$ to the pastes prepared at 80 and $95^{\circ} \mathrm{C}$ always resulted in an increase in the consistency coefficient $K$ and simultaneous decrease in the flow behaviour index $n$. As documented by Table 1, the sensitivity of these parameters to admixture of XG depended on the NPS paste concentration. However, these effects on $K$ and $n$ parameters were linear neither against the NPS paste concentration, concentration of admixed XG nor temperature of the NPS paste preparation.

Pastes without XG exhibited some thixotropy. Generally, it ceased with an increase in the paste concentration and pasting temperature. Admixture of $\mathrm{XG}$ almost always eliminated thixotropy (Table 1), however a clear opposite effect was observed in the case of $5 \%$ pastes prepared at $80^{\circ} \mathrm{C}$.

Such results (non linear changes of $K$ and $n$ values and thixotropic properties) could be rationalised in terms of cooperation of at least two phenomena whose dominant role depended on concentration of NPS in the pastes and addition of XG. One of them could be an effect of water deficiency. Undoubtedly, pasting of $2 \%$ binary pastes could be completed to a highest extent and hence enveloping swollen starch granules with XG (Hermansson et al., 1995) could be the least essential. Its role likely increased with the paste concentration and was supported by lower pasting temperature. Hence, the influence of enveloping non-pasted granules with XG could be met in 5\% binary paste prepared at $80^{\circ} \mathrm{C}$. This effect could be responsible for considerable increase in thixotropy of those pastes (Table 1). Unexpectedly, only some 5\% binary pastes exhibited residual thixotropy. Likely, other effects associated with the formation of binary paste structures (Morris, 1991) could be involved. Thorough inspection of the irregularities in thixotropy/antithixotropy of binary pastes in terms of the concentration of admixed XG might support this point of view. The most frequent irregularities in the thixotropy/ antithixotropy magnitudes were encountered for the pastes containing 0.010 and $0.075 \%$ XG. One could assume that the smallest amount $(0.010 \%)$ of $\mathrm{XG}$ in binary pastes produced uniform paste macrostructure of reduced consistency and increased flow due to either disorder caused by entrapped XG or the formation of a coupled common paste (Morris, 1991). An increase in the concentration of XG up to around $0.075 \%$ could provide a network formed of two separated phases. At XG concentration exceeding $0.075 \%$, a system of independent mutually interpenetrating networks could be formed.

Apparent viscosity of binary NPS-XG pastes was also one of their characteristic properties. These taken at constant shear rate $\left(50 \mathrm{~s}^{-1}\right)$ appeared fairly stable in time. Their average values depended on the concentration of NPS and $\mathrm{XG}$ as well as on the temperature of the paste preparation (Table 2).

Generally, the average apparent viscosity values of $2-4 \%$ NPS prepared at $80^{\circ} \mathrm{C}$ decreased upon an addition of $\mathrm{XG}$ independently on its concentration, while this parameter of the 5\% NPS increased with the addition of 0.010 and $0.075 \% \mathrm{XG}$ and decreased upon the addition of $0.150 \%$ XG. Such an irregularity can be explained in terms of competition for water molecules in water-deficient systems.

The apparent viscosity of $3-5 \%$ NPS prepared at $95^{\circ} \mathrm{C}$ decreased upon an addition of XG independently on its concentration, while in the 2\% NPS an increase upon the addition of 0.075 and $0.150 \% \mathrm{XG}$ and decrease upon the addition of $0.010 \%$ XG was observed. Noted irregularities resulted from low concentration of the whole system in which the apparent viscosity was dependent on the casual location of the XG molecules in the bulk system (Mandala et al., 2002; Sikora et al., 2015). It seems that pasting of $2 \%$ NPS-XG pastes was highly completed and hence enveloping swollen starch granules with XG was not so important (Hermansson et al., 1995). 
T a b l e 1. Parameters of the rheological Ostwald - de Waele model and area of the hysteresis loop for pastes of potato starch (NPS) without and with the xanthan gum $(\mathrm{XG})$ admixture

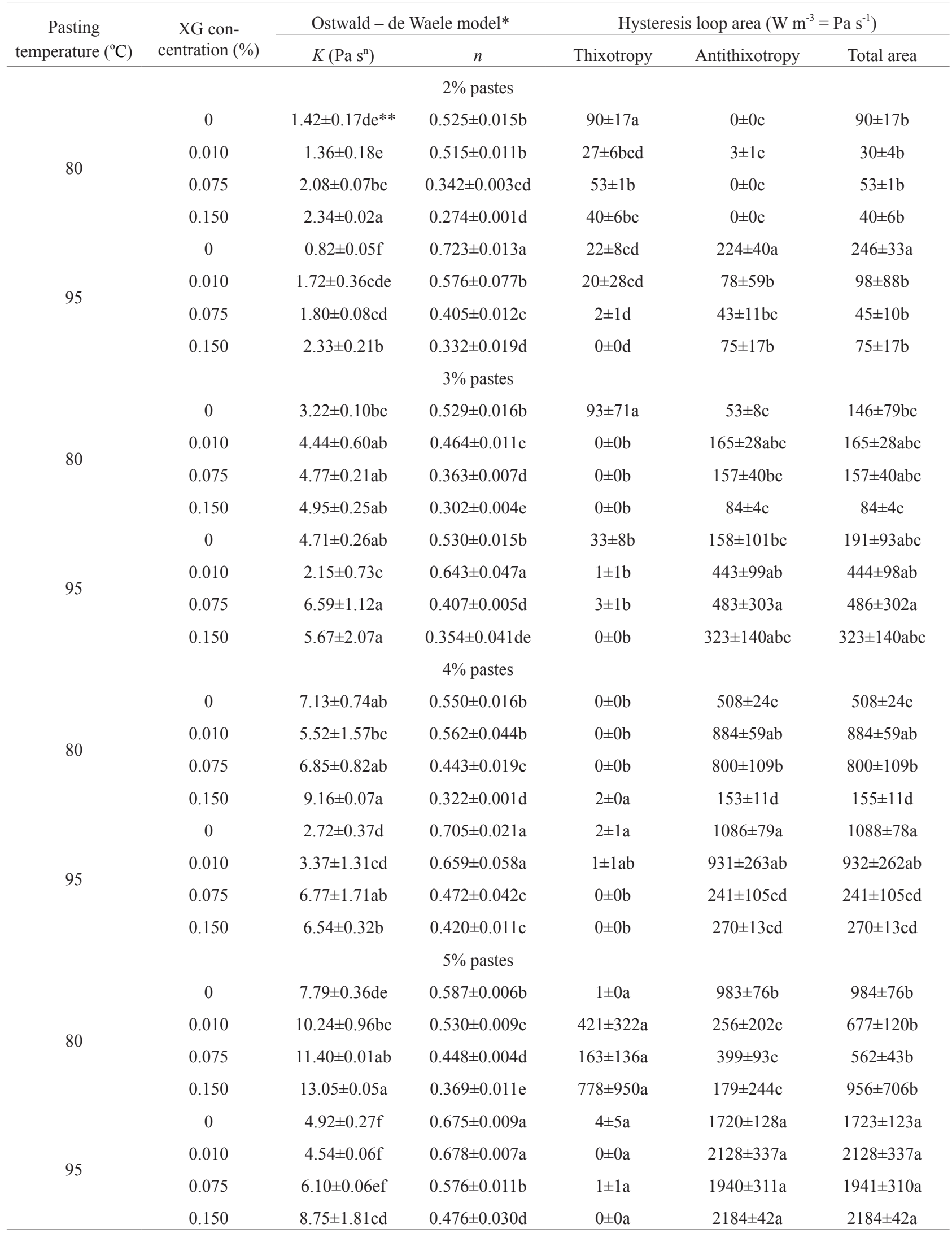

$* K$ - consistency coefficient, $n$ - flow behaviour index. In all cases correlation coefficient was in the range of $\mathrm{R}^{2}>0.996 . * * \mathrm{Different}$ characters in columns (for each starch concentration) point to statistically essential differences at $\alpha=0.05$. 
T a b l e 2. Average apparent viscosities of the NPS-XG binary pastes taken at constant shear of $50 \mathrm{~s}^{-1}$

\begin{tabular}{|c|c|c|c|}
\hline \multicolumn{2}{|c|}{$\begin{array}{c}\text { Paste } \\
\text { concentration }(\%)\end{array}$} & \multicolumn{2}{|c|}{$\begin{array}{l}\text { Average apparent viscosities (Pa s) } \\
\text { of the paste prepared at }\end{array}$} \\
\hline NPS & $\mathrm{XG}$ & $80^{\circ} \mathrm{C}$ & $95^{\circ} \mathrm{C}$ \\
\hline \multirow{4}{*}{2} & 0 & $0.243 \pm 0.007 \mathrm{fg}^{*}$ & $0.340 \pm 0.006 \mathrm{i}$ \\
\hline & 0.010 & $0.186 \pm 0.013 \mathrm{~g}$ & $0.329 \pm 0.010 \mathrm{i}$ \\
\hline & 0.075 & $0.144 \pm 0.006 \mathrm{~g}$ & $0.402 \pm 0.004 \mathrm{ghi}$ \\
\hline & 0.150 & $0.144 \pm 0.000 \mathrm{~g}$ & $0.497 \pm 0.003 \mathrm{fgh}$ \\
\hline \multirow{4}{*}{3} & 0 & $0.795 \pm 0.076 \mathrm{~d}$ & $0.615 \pm 0.075 f$ \\
\hline & 0.010 & $0.575 \pm 0.049 \mathrm{e}$ & $0.516 \pm 0.008 \mathrm{fg}$ \\
\hline & 0.075 & $0.368 \pm 0.018 \mathrm{f}$ & $0.435 \pm 0.047 \mathrm{ghi}$ \\
\hline & 0.150 & $0.316 \pm 0.005 \mathrm{fg}$ & $0.384 \pm 0.015 \mathrm{hi}$ \\
\hline \multirow{4}{*}{4} & 0 & $1.240 \pm 0.021 \mathrm{c}$ & $1.040 \pm 0.013 \mathrm{c}$ \\
\hline & 0.010 & $1.093 \pm 0.136 \mathrm{c}$ & $1.045 \pm 0.028 \mathrm{c}$ \\
\hline & 0.075 & $0.794 \pm 0.065 \mathrm{~d}$ & $0.895 \pm 0.045 \mathrm{~d}$ \\
\hline & 0.150 & $0.622 \pm 0.018 \mathrm{e}$ & $0.762 \pm 0.032 \mathrm{e}$ \\
\hline \multirow{4}{*}{5} & 0 & $1.524 \pm 0.193 \mathrm{ab}$ & $1.476 \pm 0.039 \mathrm{a}$ \\
\hline & 0.010 & $1.654 \pm 0.140 \mathrm{a}$ & $1.488 \pm 0.025 \mathrm{a}$ \\
\hline & 0.075 & $1.461 \pm 0.004 b$ & $1.433 \pm 0.168 \mathrm{a}$ \\
\hline & 0.150 & $1.143 \pm 0.028 \mathrm{c}$ & $1.258 \pm 0.062 b$ \\
\hline
\end{tabular}

*Different characters in columns point to statistically essential differences at $\alpha=0.05$.

Also fairly stable in time were apparent viscosities measured involving the in-shear structural recovery test with determination of the degree of structure recovery (Wang et al., 2009; 2010). These values differed from these collected at constant shear rate (Table 3).

Systems with DSR equal to unity are regarded as stable. Careful inspection of Table 3 leads to the finding of two such systems (bolded). These are $4 \%$ NPS with $0.010 \%$ XG prepared at $80^{\circ} \mathrm{C}$ and $5 \%$ NPS with $0.075 \%$ XG prepared at $80^{\circ} \mathrm{C}$. The in-shear structure recovery test is a test measuring thixotropy and allows the detection of systems which show stability/instability in time as described in Adamczyk et al. (2012). From this point of view, these systems can be compared to modified starches, as they are produced to deliver also stability in time.

In this paper a focus is shown on the possibility of substitution of OS (E1404) with NPS-XG binary mixtures.

The OS pastes were non-Newtonian, shear thinning fluids (Fig. 1a, Table 4). With an increase of their concentration, an increase of the shear stress values (particularly at higher shear rates - Fig. 1a) and apparent viscosities, both at shear rate of $50 \mathrm{~s}^{-1}$ (Fig. 1c) and in each step of the in-shear structural recovery test (Fig. 1b), was observed. Moreover, in the whole range of the shear rates applied almost all OS pastes demonstrated higher shear stress values compared to those of NPS pastes of the same concentration when pasted at $95^{\circ} \mathrm{C}$ (Sikora et al., 2015). 3\% OS pastes showed similar shear stress to the corresponding NPS pastes. These results are confirmed by the literature (Pietrzyk and Fortuna, 2006; Fortuna et al., 2004), where OS oxidised by sodium (I) chlorate had much lower shear stresses as compared to NPS, which was explained in terms of hydrolysis of the modified starch. Observed differences can result from the different properties of NPS (Sikora $e t$ al., 2015) and potato starch used for the production of OS. The increase in the concentration of the OS pastes was accompanied by an increase in consistency coefficient $K$ (Table 4). Simultaneously, flow behaviour index $n$ was considerably below unity and it was similar for all modified starch pastes. The consistency coefficients $K$ of all OS pastes were higher than these for corresponding NPS pastes (Sikora et al., 2015). This confirmed higher apparent viscosity of OS pastes. The samples of OS (excluding 3\% OS) had lower flow behaviour index $n$ than those of NPS (Sikora et al., 2015), which suggests greater non-Newtonian character (the samples were more shear-thinned). The course of the flow curve (Fig. 1a), consistent with the clockwise direction and the values of hysteresis loop areas of thixotropy (Table 4), suggested that the OS pastes had thixotropic properties, the greater the higher the concentration of OS applied. However, such behaviour of the OS samples was not confirmed by the results of the apparent viscosity measurements at $50 \mathrm{~s}^{-1}$ (Fig. 1c) as well as of the degree of the structure recovery DSR values (Table 4). Small changes of the apparent viscosity during shearing at $50 \mathrm{~s}^{-1}$ and values of DSR close to 1 indicated a high rheological stability of the OS pastes, regardless of their concentration.

The values of shear stress and consistency coefficient (Fig. 1a, Table 4) allow the assumption that in order to obtain mixed pastes with shear stresses and parameters of the Ostwald-de Waele model similar to those of OS pastes an addition of XG should mainly increase the apparent viscosity and pseudoplasticity of the NPS samples. The values of hysteresis loop areas are less significant as they do not describe the phenomena of thixo-antithixotropy quantitatively (Adamczyk et al., 2012; Barnes, 1997; Steffe, 1996). The more important is an addition of XG to stabilise the pastes, that is the DSR values (Table 3 ) should be close to 1 as well as changes of the apparent viscosity at $50 \mathrm{~s}^{-1}$ should be small and their values high (Table 2). Additionally, having in mind the fact that the DSR is the ratio of mean value of apparent viscosity in the first $120 \mathrm{~s}$ of the fifth step of shearing to the mean value of apparent viscosity in the third step, samples with similar DSR in reality can significantly 
T a b l e 3. Average apparent viscosities and the DSR of $2-5 \%$ NPS-XG binary pastes taken by the in-shear structural recovery test

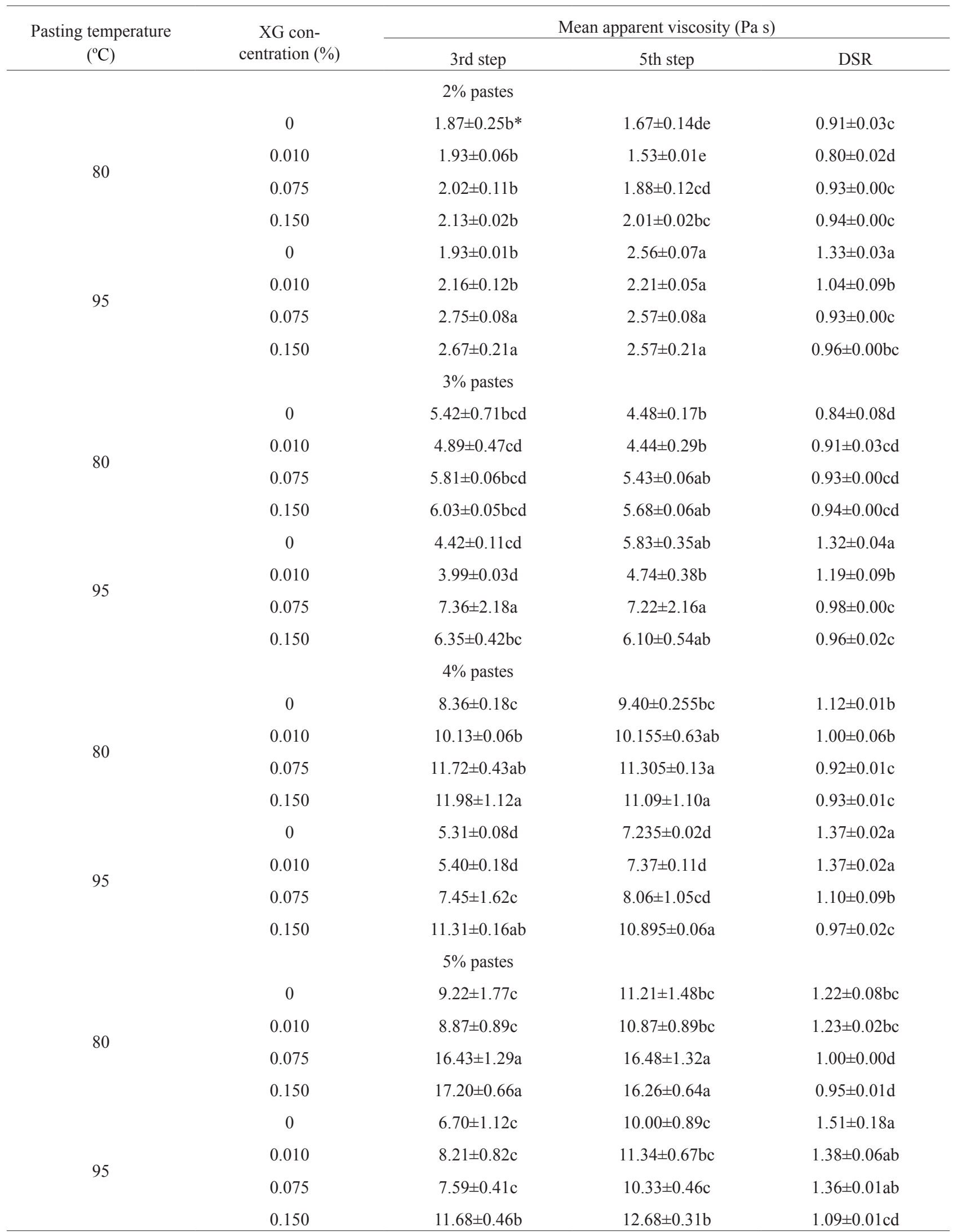

*Different characters in columns (for each starch concentration) point to statistically essential differences at $\alpha=0.05$. 


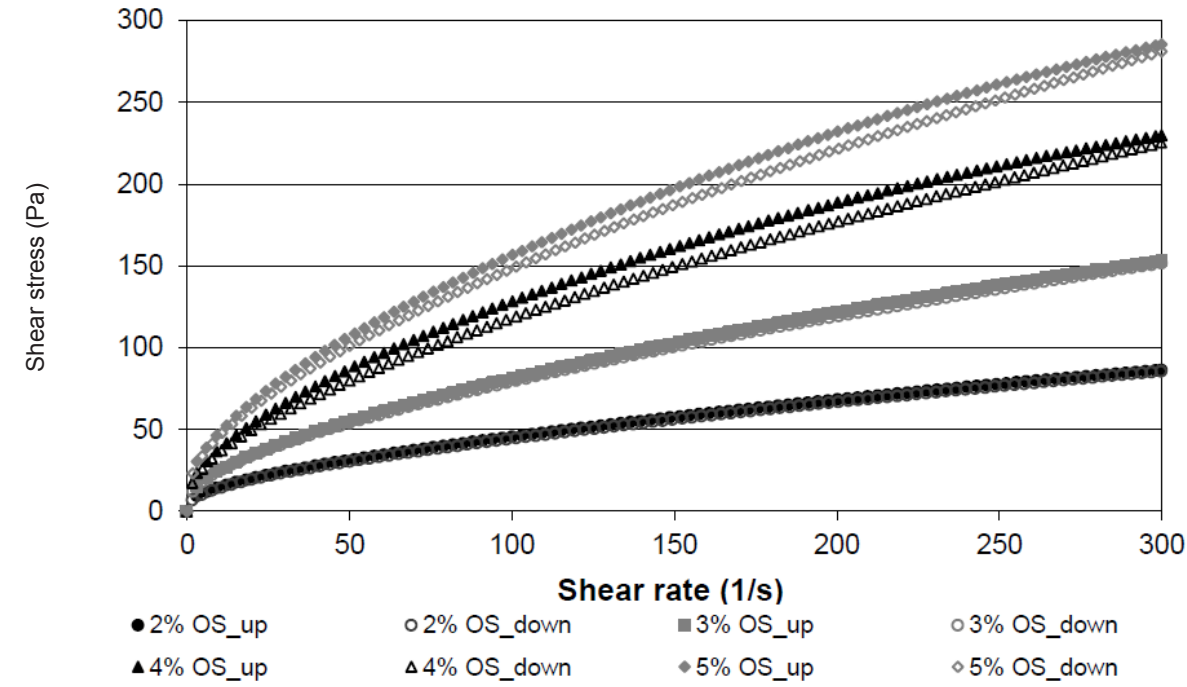

$\mathrm{b}$

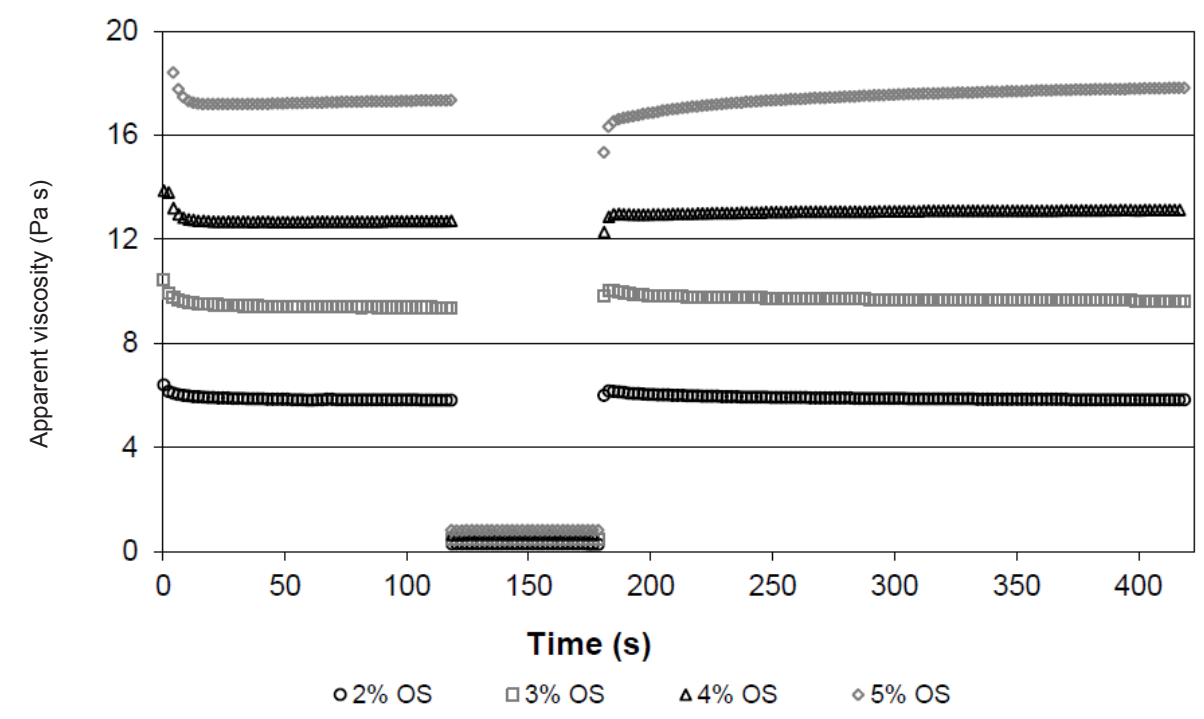

c

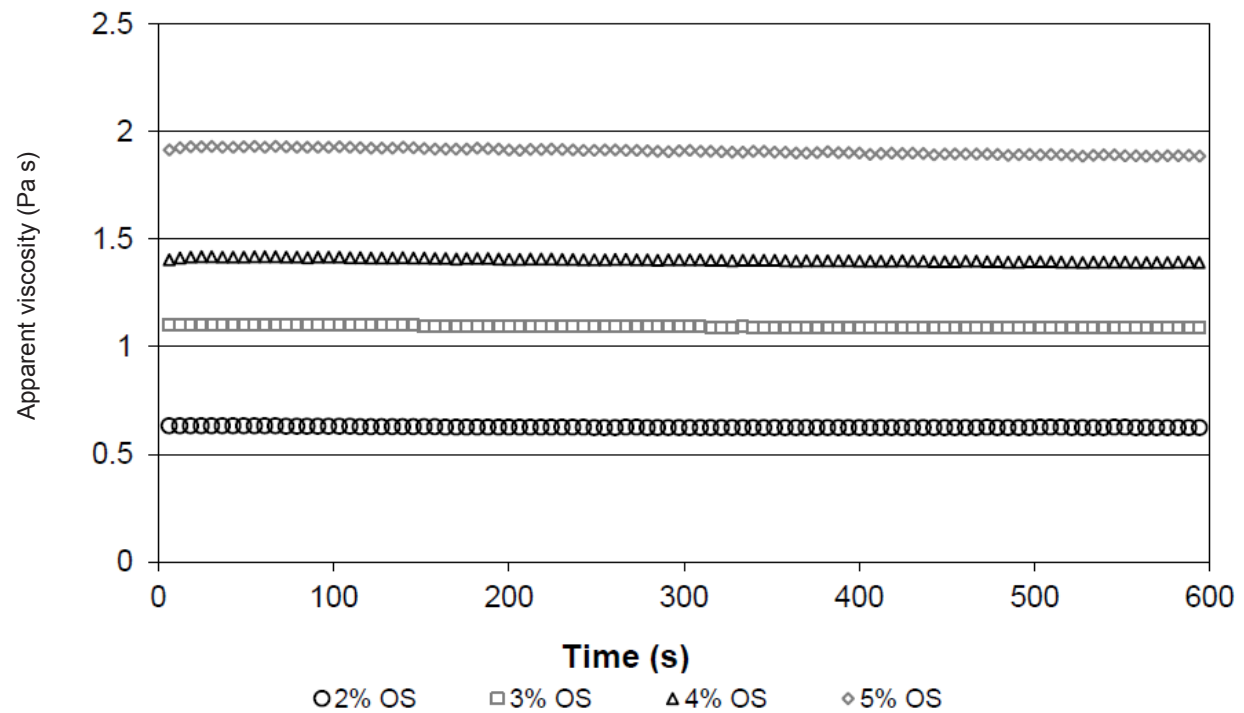

Fig. 1. Flow curves (a), results of the in-shear structural recovery test with pre-shearing (b) and apparent viscosities at $50 \mathrm{~s}^{-1}$ (c) of $2-5 \%$ OS starch pastes. 
T a b l e 4. Parameters of the Ostwald - de Waele rheological model and areas of hysteresis loops for 2-5\% OS and similar* results obtained for the mixed NPS:XG pastes

\begin{tabular}{|c|c|c|c|c|c|}
\hline \multirow{2}{*}{ Samples } & \multicolumn{2}{|c|}{$\begin{array}{l}\text { Parameters of the Ostwald de Waele } \\
\text { model** }\end{array}$} & \multicolumn{3}{|c|}{ Area of the hysteresis loop $\left(\mathrm{W} \mathrm{m}^{-3}=\mathrm{Pa} \mathrm{s}\right)$} \\
\hline & $K\left(\mathrm{~Pa} \mathrm{~s}^{\mathrm{n}}\right)$ & $n(-)$ & Thixotropy & Antithixotropy & Total area \\
\hline \multicolumn{6}{|l|}{ Samples of OS } \\
\hline $2 \%$ & $3.47 \pm 0.03 \mathrm{c} \mathrm{d} * * *$ & $0.563 \pm 0.005 \mathrm{ab}$ & $125 \pm 58 \mathrm{bc}$ & $4 \pm 4 b$ d & $129 \pm 54 b \mathrm{~d}$ \\
\hline $3 \%$ & $6.06 \pm 0.14 b \mathrm{c}$ & $0.566 \pm 0.001 \mathrm{~b}$ & $203 \pm 11 \mathrm{abc}$ & $15 \pm 0 \mathrm{a} \mathrm{d}$ & $218 \pm 11 \mathrm{~b} \mathrm{~cd}$ \\
\hline $4 \%$ & $10.73 \pm 0.67 \mathrm{a} \mathrm{b}$ & $0.540 \pm 0.009 \mathrm{c} \mathrm{b}$ & $1091 \pm 16 \mathrm{a}$ & $5 \pm 3 \mathrm{~b} \mathrm{~d}$ & $1096 \pm 16 a \mathrm{~b}$ \\
\hline $5 \%$ & $12.75 \pm 1.53 \mathrm{a}$ & $0.547 \pm 0.008 \mathrm{bc}$ & $939 \pm 446 \mathrm{ab}$ & $9 \pm 2 \mathrm{ab} \mathrm{d}$ & $947 \pm 444 \mathrm{a}$ bc \\
\hline \multicolumn{6}{|c|}{ Samples similar to $2 \%$ OS } \\
\hline $3 \% \mathrm{NPS}+0.010 \% \mathrm{XG}$ at $95^{\circ} \mathrm{C}$ & $2.15 \pm 0.73 \mathrm{~d}$ & $0.643 \pm 0.047 \mathrm{a}$ & $1 \pm 1 \mathrm{c}$ & $443 \pm 99 \mathrm{c}$ & $444 \pm 98$ bcd \\
\hline \multicolumn{6}{|c|}{ Samples similar to $3 \%$ OS } \\
\hline $4 \% \mathrm{NPS}+0.010 \% \mathrm{XG}$ at $80^{\circ} \mathrm{C}$ & $5.52 \pm 1.57 \mathrm{c}$ & $0.562 \pm 0.044 \mathrm{~b}$ & $0 \pm 0 \mathrm{c}$ & $884 \pm 59 b$ & $884 \pm 59 \mathrm{bc}$ \\
\hline $5 \% \mathrm{NPS}+0.075 \% \mathrm{XG}$ at $95^{\circ} \mathrm{C}$ & $6.10 \pm 0.06 \mathrm{c}$ & $0.576 \pm 0.011 \mathrm{~b}$ & $1 \pm 1 \mathrm{c}$ & $1940 \pm 311 \mathrm{a}$ & $1941 \pm 310 \mathrm{a}$ \\
\hline \multicolumn{6}{|c|}{ Samples similar to $4 \%$ OS } \\
\hline $5 \% \mathrm{NPS}+0.010 \% \mathrm{XG}$ at $80^{\circ} \mathrm{C}$ & $10.24 \pm 0.96 b$ & $0.530 \pm 0.009 \mathrm{~b}$ & $421 \pm 322 \mathrm{abc}$ & $256 \pm 202 \mathrm{~cd}$ & $677 \pm 120 \mathrm{bcd}$ \\
\hline \multicolumn{6}{|c|}{ Samples similar to $5 \%$ OS } \\
\hline $5 \% \mathrm{NPS}+0.150 \% \mathrm{XG}$ at $80^{\circ} \mathrm{C}$ & $13.05 \pm 0.05 \mathrm{a}$ & $0.369 \pm 0.011 \mathrm{c}$ & $778 \pm 950 \mathrm{abc}$ & $179 \pm 244 \mathrm{~cd}$ & $956 \pm 706 b c$ \\
\hline
\end{tabular}

*Samples selected on the basis of flow curves similarity. $* * K$ - consistency coefficient, $n$ - flow behavior index. In all cases $\mathrm{R}^{2}>0.996$. $* * *$ Different characters in columns denote statistically essential differences at $\alpha=0.05$.

differ from one another with regard to the rheological properties. By reason of this the NPS:XG mixed pastes should have values of apparent viscosity similar to OS pastes in the particular steps of shearing (Tables 2 and 4). This is extremely important in steps 3 and 5 because relatively high values of shear rates evoke higher differences.

Comparisons of the rheological properties of the binary NPS-XG pastes with the properties of the OS pastes brought different results depending on the above mentioned criteria of similarity (Tables 4 and 5). Thus, when the comparisons were made based on the shear stress values and parameters of the Ostwald - de Waele model it was found that $3 \%$ NPS paste with $0.010 \%$ XG prepared at $95^{\circ} \mathrm{C}$ best fitted the properties of $2 \%$ OS paste (Table 4 ). Pastes containing $4 \%$ NPS paste with $0.010 \% \mathrm{XG}$ prepared at $80^{\circ} \mathrm{C}$ and $5 \%$ pastes of NPS with $0.075 \%$ XG pasted at $95^{\circ} \mathrm{C}$ exhibited the properties of 3\% OS paste (Table 4, Fig. 2a). Apart from that, $5 \%$ NPS paste with $0.010 \%$ XG prepared at $80^{\circ} \mathrm{C}$ resembled the properties of $4 \%$ OS paste and $5 \%$ NPS paste with $0.150 \%$ XG prepared at $80^{\circ} \mathrm{C}$ mimed the properties of $5 \%$ OS paste (Table 4 ).
When apparent viscosities measured at constant shear were regarded, properties of $2 \%$ OS paste could be mimed by $3 \%$ NPS paste with $0.010 \%$ XG prepared at $80^{\circ} \mathrm{C}$ (Table 5). Also binary $4 \%$ NPS paste with $0.010 \%$ XG prepared at $80^{\circ} \mathrm{C}$ was similar to $3 \%$ OS pastes (Table 5, Fig. 2 c), as well as binary $5 \%$ NPS pastes with $0.010 \%$ XG prepared at $95^{\circ} \mathrm{C}$, sheared at $50 \mathrm{~s}^{-1}$ (Table 5), had apparent viscosity close to that of $4 \%$ AcDP paste. One may see that when apparent viscosity at constant shear rate was adopted as the similarity criterion no combination of NPS with XG could provide a substitute for $5 \%$ OS paste.

When apparent viscosity measured by the in-shear structural recovery test was taken under consideration, 3\% NPS paste with $0.075 \% \mathrm{XG}$ prepared at $80^{\circ} \mathrm{C}$ as well as $3 \%$ NPS paste with $0.150 \%$ XG prepared at the same temperature best resembled $2 \%$ OS paste. Other NPS-XG binary paste substitutes for 3 to $5 \%$ OS pastes are listed in Table 5 and/or in Fig. 2b.

Because of intervention of the interaction energy between components of binary pastes and components of thickened system it should be taken under consideration that similarity of rheological and thixotropic properties of 
a

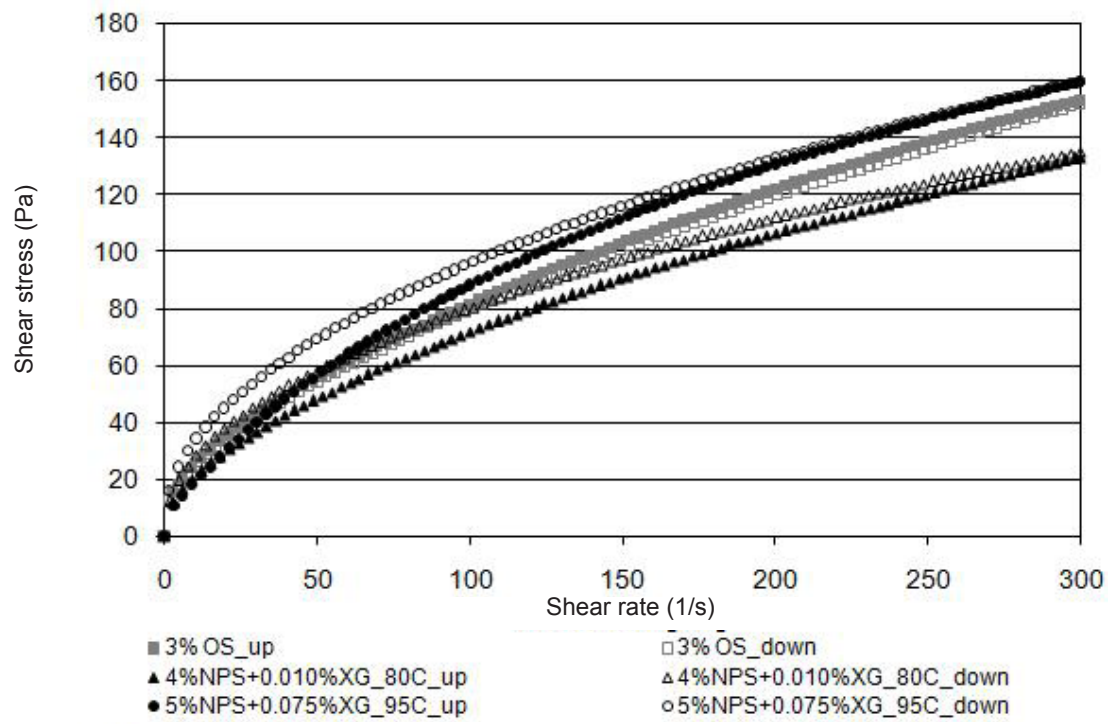

$\mathrm{b}$
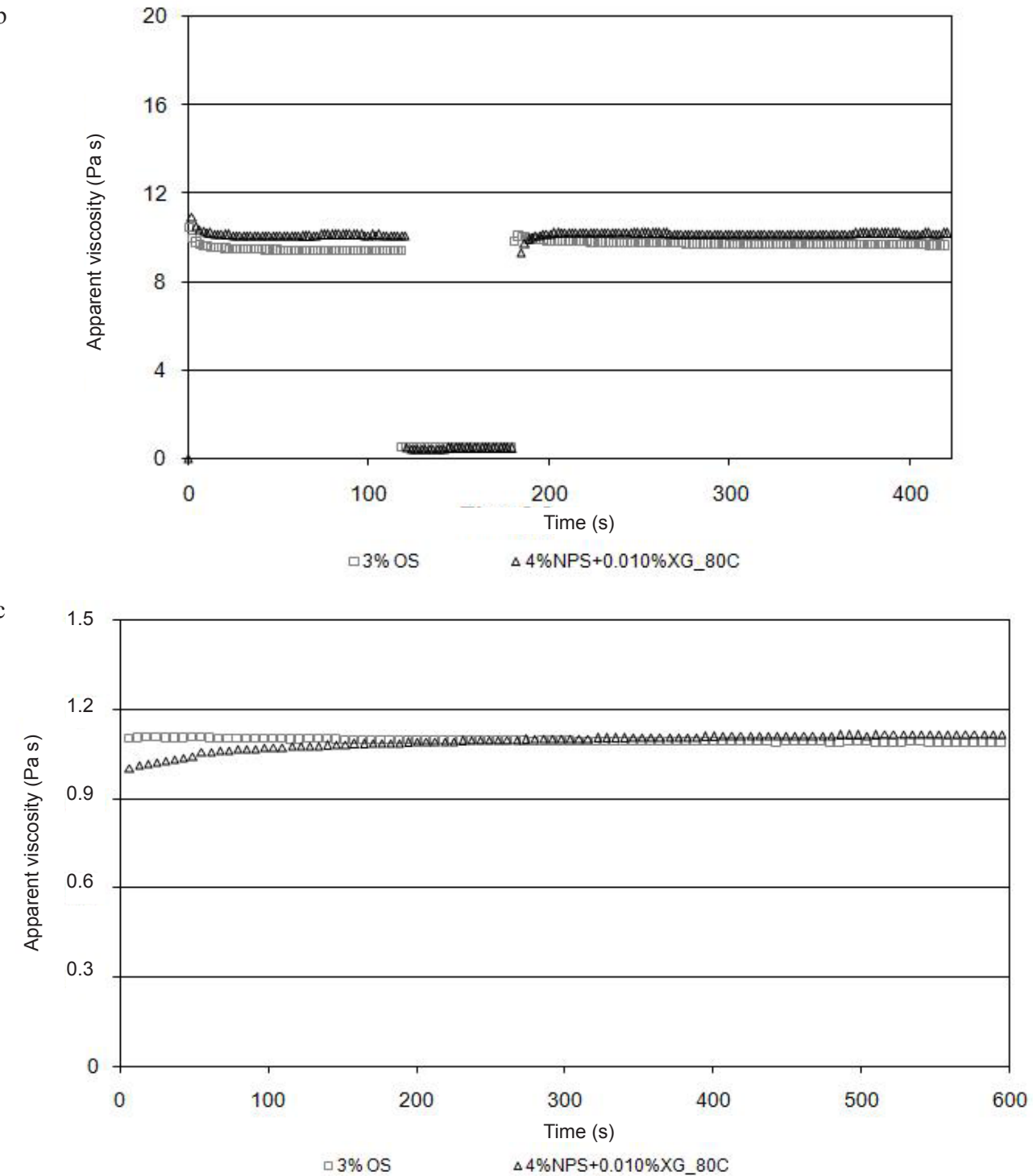

Fig. 2. Flow curves (a), results of the in-shear structural recovery test with pre-shearing (b) and apparent viscosities at $50 \mathrm{~s}^{-1}$ (c) of $3 \%$ OS and NPS:XG samples with properties similar to $3 \%$ OS pastes. 
T a b l e 5. Average apparent viscosity in the third and the fifth (in the first $120 \mathrm{~s}$ ) steps of in-shear structural recovery test as well as the DSR and apparent viscosities at $50 \mathrm{~s}^{-1}$ of $2-5 \%$ OS pastes and similar* results obtained for the mixed NPS:XG pastes

\begin{tabular}{|c|c|c|c|c|}
\hline \multirow{2}{*}{ Samples } & \multicolumn{2}{|c|}{ Apparent viscosity (Pa s) } & \multirow{2}{*}{ DSR } & \multirow{2}{*}{$\begin{array}{c}\text { Apparent viscosity } \\
\text { at } 50 \mathrm{~s}^{-1}(\mathrm{~Pa} \mathrm{~s})\end{array}$} \\
\hline & step 3 & step 5 & & \\
\hline \multicolumn{5}{|c|}{ Samples of OS } \\
\hline $2 \%$ & $5.88 \pm 0.06 \mathrm{e}^{*}$ & $5.97 \pm 0.01 \mathrm{~d}$ & $1.02 \pm 0.01 \mathrm{ab}$ & $0.628 \pm 0.011 \mathrm{~d}$ \\
\hline $3 \%$ & $9.46 \pm 0.10 \mathrm{~d}$ & $9.77 \pm 0.07 \mathrm{c}$ & $1.04 \pm 0.01 \mathrm{a}$ & $1.097 \pm 0.028 \mathrm{c}$ \\
\hline $4 \%$ & $12.59 \pm 0.11 b$ & $12.83 \pm 0.11 b$ & $1.02 \pm 0.00 \mathrm{ab}$ & $1.410 \pm 0.148 b$ \\
\hline $5 \%$ & $17.41 \pm 1.74 \mathrm{a}$ & $17.17 \pm 1.88 \mathrm{a}$ & $0.99 \pm 0.01 \mathrm{bc}$ & $1.919 \pm 0.075 \mathrm{a}$ \\
\hline \multicolumn{5}{|c|}{ Similarities in apparent viscosity test } \\
\hline similar to $2 \%$ OS & \multicolumn{3}{|c|}{$3 \% \mathrm{NPS}+0.010 \% \mathrm{XG}$ at $80^{\circ} \mathrm{C}$} & $0.575 \pm 0.049 \mathrm{~d}$ \\
\hline similar to $3 \%$ OS & \multicolumn{3}{|c|}{$4 \% \mathrm{NPS}+0.010 \% \mathrm{XG}$ at $80^{\circ} \mathrm{C}$} & $1.093 \pm 0.136 \mathrm{c}$ \\
\hline similar to $4 \%$ OS & \multicolumn{3}{|c|}{$5 \% \mathrm{NPS}+0.010 \% \mathrm{XG}$ at $95^{\circ} \mathrm{C}$} & $1.488 \pm 0.025 b$ \\
\hline \multicolumn{5}{|c|}{ Similarities in in-shear recovery test (at $80^{\circ} \mathrm{C}$ ) } \\
\hline \multicolumn{5}{|c|}{ Samples similar to $2 \%$ OS } \\
\hline $3 \%$ NPS $+0.075 \%$ XG & $5.81 \pm 0.00 \mathrm{e}$ & $5.43 \pm 0.06 \mathrm{~d}$ & $0.93 \pm 0.00 \mathrm{~d}$ & \\
\hline $3 \% \mathrm{NPS}+0.150 \% \mathrm{XG}$ & $6.03 \pm 0.05 \mathrm{e}$ & $5.68 \pm 0.06 \mathrm{~d}$ & $0.94 \pm 0.00 \mathrm{~d}$ & \\
\hline \multicolumn{5}{|c|}{ Samples similar to $3 \%$ OS } \\
\hline $4 \% \mathrm{NPS}+0.010 \% \mathrm{XG}$ & $10.13 \pm 0.06 \mathrm{~cd}$ & $10.16 \pm 0.63 c$ & $1.00 \pm 0.06 \mathrm{ab}$ & \\
\hline \multicolumn{5}{|c|}{ Samples similar to $4 \%$ OS } \\
\hline $4 \% \mathrm{NPS}+0.075 \% \mathrm{XG}$ & $11.72 \pm 0.43 \mathrm{bc}$ & $11.305 \pm 0.13 \mathrm{bc}$ & $0.92 \pm 0.01 \mathrm{~d}$ & \\
\hline $4 \% \mathrm{NPS}+0.150 \% \mathrm{XG}$ & $11.98 \pm 1.12 b$ & $11.09 \pm 1.10 \mathrm{bc}$ & $0.93 \pm 0.01 \mathrm{~d}$ & \\
\hline \multicolumn{5}{|c|}{ Samples similar to $5 \%$ OS } \\
\hline $5 \% \mathrm{NPS}+0.075 \% \mathrm{XG}$ & $16.43 \pm 1.29 \mathrm{a}$ & $16.48 \pm 1.32 \mathrm{a}$ & $1.00 \pm 0.00 \mathrm{ab}$ & \\
\hline $5 \% \mathrm{NPS}+0.150 \% \mathrm{XG}$ & $17.20 \pm 0.66 \mathrm{a}$ & $16.26 \pm 0.64 \mathrm{a}$ & $0.95 \pm 0.01 \mathrm{~cd}$ & \\
\hline
\end{tabular}

given OS pastes and their binary NPS-XG substitutes taken in vitro does not mean that their performance under in vivo conditions would also be similar.

Amylose (Am) - amylopectin (Amp) is a system forming a separate phase system in which substantial Am-Amp interactions are lacking (Hermansson et al., 1995; Lii et al., 2002). Nevertheless, at certain Am:Amp proportions in the system a considerable increase in viscosity associated with fair time dependent stability takes place. It could be afforded when the pastes contained either low concentration of Am in Amp or low concentration of Amp in Am.
Such results could suggest that also under such conditions an increased viscosity of NPS-XG binary paste could be afforded.

\section{CONCLUSIONS}

1. Binary mixtures of normal potato starch pastes with xanthan gum, both being anionic polysaccharides, showed an effect of thickening provided the concentration of xanthan gum in normal potato starch did not exceed $0.150 \%$.

2. Temperatures of paste preparation as well as the normal potato starch paste concentration were also factors influencing the thickening effect. 
3. All binary systems with $2 \%$ normal potato starch pastes prepared both at 80 and $95^{\circ} \mathrm{C}$ as well as with $5 \%$ normal potato starch pastes prepared at $80^{\circ} \mathrm{C}$ were thixotropic regardless of the concentration of xanthan gum added. The other normal potato starch-xanthan gum pastes were purely antithixotropic.

4. Pastes of oxidised starch had high rheological stability.

5. Rheological properties of some of the binary normal potato starch-xanthan gum blends resemble such properties of pastes of oxidised starch.

6. Rheological properties of binary mixtures can be tailored.

Conflict of interest: The Authors do not declare conflict of interest.

\section{REFERENCES}

Achayuthakan P. and Suphantharika M., 2008. Pasting and rheological properties of waxy corn starch as affected by guar gum and xanthan gum. Carbohydr. Polym., 71, 9-17.

Adamezyk G., Sikora M., and Krystyjan M., 2012. Methods for measuring thixotropy of food products (in Polish). Żywn. Nauka. Technol. Jakość, 19, 19-34.

Alloncle M., Lefebvre J., Llamas G., and Doublier J., 1989. A rheological characterization of cereal starch-galactomannan mixtures. Cereal Chem., 66, 90-93.

Appelqvist I.A.M. and Debet M.R.M., 1997. Starch - biopolymer interactions - A review, Food Rev. Int., 13, 163-224.

Arocas A., Sanz T., and Fiszman S.M., 2009. Improving effect of xanthan and locust bean gums on the freeze-thaw stability of white sauces made with different native starches. Food Hydrocoll., 23, 2478-2484.

Baranowska H.M., Sikora M., Kowalski S., and Tomasik P., 2008. Interactions of potato starch with selected polysaccharide hydrocolloids as measured by low-field NMR. Food Hydrocoll., 22, 336-345.

Barnes H.A., 1997. Tixotropy - a review. J. Non-Newtonian Fluid Mech., 70, 1-33.

Codex Alimentarius, 2014. General Standards for Food Additives, FAO/WHO, Codex Stan 192-1995, Revised 2014.

Compendium of Food Additive Specifications, 2011. Food and Agriculture Organization of the United Nations.

Fortuna T., Galkowska D., and Juszczak L., 2004. Comparison of rheological properties of selected preparations of modified starches (in Polish). Acta Sci. Pol., Technol. Aliment., 03, 1, 21-32.

Hermansson A.M., Kidman S., and Svegmark K., 1995. A phase-separated biopolymer system. In: Biopolymer Mixtures (Eds S.E. Harding, S.E. Hill, J.R. Mitchell). Nothingham University Press, Nothingham., UK, pp. 225-245.

Kaur B., Ariffin F., Bhat R., and Karim A.A., 2012. Progress in starch modification in the last decade. Food Hydrocoll., 26, 398-404.

Kowalski S., Sikora M., Tomasik P., and Krystyjan M., 2008. Starch polysaccharide hydrocolloid gels. Polimery, 53, 457-464.
Krystyjan M., Adamczyk G., Sikora M., and Tomasik P., 2013. Long-term storage stability of selected potato starch - nonstarchy hydrocolloid binary pastes. Food Hydrocoll., 31, 270-276.

Le Than J., Blaszczak W., and Lewandowicz G., 2007. Digestibility $v s$. structure of food grade modified starches. EJPAU, 10

Lii C.Y., Tomasik P., Hung W.L, and Lai M.F., 2002. Polysaccharide - polysaccharide interactions in pastes. Pol. J. Food Nutr. Sci., 11/52, 29-33.

Mandala I.G., Palogou E.D., and Kostaropolulos A.E., 2002. Influence of preparation and storage conditions on texture of xanthan gum-starch mixtures, J. Food Eng., 53, 27-38.

Mezger T.G., 2002. Rotational tests. In The rheology handbook: For users of rotational and oscillatory rheometers (Ed. U. Zorll). Vincentz Verlag, Hannover, 55-68.

Morris V.J., 1991. Weak and strong polysaccharide pastes. In: Food Polymers, Pastes Colloids (Ed. E. Dickinson). The Royal Society of Chemistry, Cambridge, UK.

Pietrzyk S. and Fortuna T., 2006. Changes in physico-chemical properties of potato starch caused by oxidation process (in Polish). Zesz. Probl. Post. Nauk Roln., 511, 627-637.

Ramsden L., 2004. Plant and algal gums and mucilages. In: Chemical and functional propertied of food saccharides (Ed. P. Tomasik). CRC Press, Boca Raton, FL, USA.

Rutkowski A., Gwiazda S., and Dąbrowski K., 2003. Compendium of food additives (in Polish). Hortimex, Konin, Poland.

Sikora M., Adamczyk G., Krystyjan M., Dobosz A., Tomasik P., Berski W., Lukasiewicz M., and Izak P., 2015. Thixotropic properties of normal potato starch depending on the degree of the granules pasting. Carbohydr. Polym., $121,254-264$

Sikora M., Badrie N., Deisingh A.K., and Kowalski S., 2008a. Sauces and dressings: A review of properties and applications. Crit. Revs. Food Sci. Nutr., 48, 50-77.

Sikora M., Kowalski S., and Tomasik P., 2008b. Binary hydrocolloids from starches and xanthan gum. Food Hydrocoll., 22, 943-952.

Sikora M., Kowalski S., Tomasik P., and Sady M., 2007. Rheological and sensory properties of dessert sauces thickened by starch - xanthan gum combinations. J. Food Eng., $79,1144-1151$

Sikora M., Tomasik P., and Krystyjan M., 2010. Characterization of potato starch fractions and their interactions with hydrocolloids. Starch/Stärke, 62, 341-349.

Singh N., Singh J., Kaur L., Sodhi N.S., and Gill B.S., 2003. Morphological, thermal and rheological properties of starches from different botanical sources. Food Chem., 81, 219-231.

Steffe J.F., 1996. Rheological methods in food process engineering. Freeman Press, East Lansing, MI, USA.

Swinkels J.J.M., 1985. Composition and properties of commercial native starches. Starch/Stärke, 37, 1-5.

Tegge G., 2010. Starch and its derivatives (in Polish). Polish Society of Food Technologists', Kraków, Poland.

Tomasik P. and Schilling C.H., 1998a. Complexes of Starch with Inorganic Guests. Adv. Carbohydr. Chem. Biochem., $53,263-343$. 
Tomasik P. and Schilling C.H., 1998b. Complexes of Starch with Organic Guests. Adv. Carbohydr. Chem. Biochem., $53,345-426$.

Wang B., Li D., Wang L.-J., and Özkan N., 2010. Anti-thixotropic properties of waxy maize starch dispersions with different pasting conditions. Carboh. Polym., 79, 1130-1139.
Wang B., Wang L.-J., Li D., Özkan N., Li S.-J., and Mao Z.-H. 2009. Rheological properties of waxy maize starch and xanthan gum mixtures in the presence of sucrose. Carboh. Polym., 77, 472-481.

Whistler R.L. and BeMiller J.N., 1977. Carbohydrate Chemistry for Food Scientists. Eagan Press, St. Paul, MN, USA. 